\title{
A IMPORTÂNCIA DE PRODUZIR E DIVULGAR EXPERIÊNCIAS DE PESQUISA E PRÁTICAS EM SAÚDE MENTAL
}

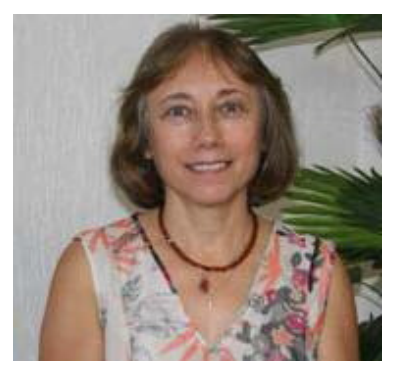

Neste volume é possível observar que a maioria dos artigos se refere ao uso de substâncias psicoativas e que os temas abordados são diversificados assim como as populações investigadas. Essa peculiaridade constitui um fator a mais para incentivar a sua leitura.

Considerando os grupos populacionais estudados, destacam-se as gestantes, cujo consumo de drogas está presente no cotidiano dos serviços de saúde, porém em relação às pesquisas, trata-se de assunto pouco explorado. Talvez uma razão para isso, seja a necessidade de haver o diálogo entre o profissional que atua em obstetrícia com aquele que tem conhecimento sobre adições, portanto trata-se de um grupo numa condição que solicita uma abordagem interdisciplinar. O mesmo se aplica aos usuários de substâncias psicoativas atendidos em serviços de saúde de atendimento às Urgências e Emergências, pois ambos grupos estão expostos ao preconceito derivado das crenças relativas a quem e como devem ser ou estar as pessoas que buscam atenção à saúde nessas condições.

A expectativa em relação à gestante, baseada no senso comum, é a de uma mulher que mostre felicidade pelo seu estado e interesse pela situação do concepto, assim, pode parecer inadmissível ao profissional de saúde, que a gestante seja uma usuária de substâncias psicoativas, já que esse comportamento pode ter repercussões no estado de saúde da criança. No caso do atendimento às situações de urgências e emergências, também é esperado um tipo de paciente, em condições que apresentem alto nível de gravidade, complexidade e dependência da equipe de saúde, os pacientes usuários de substâncias psicoativas podem até se encaixar nesse perfil, desde que estejam acidentados, ou inconscientes, ou apresentando algum quadro que requeira ação imediata dos profissionais de saúde. Passado o momento crítico ou quando ele não está numa condição dessa natureza, predominam as recriminações, os julgamentos morais, o afastamento, que inclusive pode motivar o usuário a não buscar mais por atendimento ou colocar em risco à sua integridade física, no caso de não receber, no momento apropriado, o cuidado que deveria. Portanto, nada mais acertado do que desenvolver pesquisas junto a esses dois grupos vulneráveis ao preconceito, inclusive nos próprios serviços de saúde.

Em relação ao preconceito, o artigo sobre usuários de crack traz uma perspectiva pouco explorada, até porque o dependente dessa substância tem dificuldade de acesso aos serviços de saúde - a menos que os profissionais consigam estabelecer um vínculo de confiança e facilitem a sua entrada e permanência com um plano terapêutico que valorize o esforço que essa pessoa está fazendo quando vai procurar o atendimento-, é preciso alguma flexibilidade nas normas e regras do serviço. Dai, conhecer o que pensa o dependente de crack sobre o episódio de recaída, possibilita ao profissional adquirir uma compreensão maior da sua vivência, requisito imprescindível para promover a aproximação e minimizar os efeitos de julgamentos de valor e cunho moral a respeito do usuário.

Os estudantes universitários, continuam sendo alvo dos pesquisadores em substâncias psicoativas, pois há evidências suficientes de que são uma população vulnerável ao consumo das mesmas. Os artigos deste número tem como objeto estudantes da área da saúde, portanto aqueles que num dado momento de sua vida profissional podem se ver na condição de prestadores de assistência a pessoas envolvendo intercorrências, ou mesmo com problemas, decorrentes do uso abusivo ou dependência de alguma droga psicoativa. No caso específico dessa população, parece relevante pesquisar não só o consumo, mas as motivações ou razões disso, pois tais informações podem contribuir para que instituições de ensino superior reflitam sobre as condições favorecedoras ou não da saúde que são oferecidas a seus discentes, que no futuro estarão sendo responsáveis pela melhora do nível de saúde de comunidades. Não deixa de ser preocupante, para não dizer trágico, pensar que possa haver entre eles aqueles que não incorporaram por si mesmos o valor da sua saúde e, no entanto, estarão no papel de aconselhar ou cuidar da saúde de outros.

No momento atual, nada mais oportuno do que o estudo sobre os transtornos de personalidade, de certa forma eles ficaram um pouco esquecidos no cenário da atenção à saúde mental, em comparação a outros transtornos atendidos nos serviços especializados, pois diferente de outros pacientes, esse pode não ser um cliente habitual, sujeito a surtos e por isso, frequentador mais continuo dos atendimentos propostos pela equipe de saúde. A pessoa com transtorno de personalidade, pode até ser alguém que acaba sendo encaminhado a um serviço de saúde mental mais frequentemente, quando apresenta alguma comorbidades associada. É preciso saber mais sobre esses clientes, cuja abordagem requer conhecimento e habilidades interpessoais, por isso a divulgação de trabalhos que os tenham como objeto de pesquisa e agreguem conhecimento, devem servir de incentivo para a realização de outros. 
É sempre construtivo fazer revisões de literatura, no intuito de estimular a reflexão, no caso da saúde mental é quase que obrigatório, dadas as características únicas do sistema de saúde brasileiro, que não é perfeito mas, ao menos na Lei, é acessível a todos os cidadãos, Pelo muito que custou modificar uma lógica de atenção à saúde mental, que não se mostrou eficaz no passado. Há de se estar alerta para que novos erros não levem ao retrocesso e envidar esforços para chamar a atenção às deficiências e limitações como a qualidade da gestão dos serviços, do capital humano (trabalhadores de saúde), da necessidade de contratações e/ou capacitação de pessoal onde isso seja uma prioridade, tendo como objetivo principal, a melhora do cuidado aos usuários. A revisão que encerra o presente número mostra as reflexões de um grupo, a expectativa é de que o artigo motive nos leitores o desejo de elaboração de ações concretas.

Como editora da revista, tenho tido a oportunidade de fazer a leitura de todos os textos que são enviados, isso motivou o interesse em estabelecer um "diálogo" com os pesquisadores que nos enviam seus trabalhos, no intuito de atualizar sua informação a respeito do campo da comunicação e disseminação do conhecimento científico particularmente de suas demandas, considerando o momento crescente de incentivo à produção de pesquisa, tendência essa que afeta em âmbito global, com mais ênfase, às instituições de ensino superior.

Neste editorial, o foco dos comentários, sobre a razão de ser de uma revista científica muitos fazem esse questionamento e podem dar várias respostas, de acordo com interesses específicos e particulares. Porém, no mundo acadêmico- científico, ela tem um papel de grande relevância, pois uma revista científica consiste num periódico que uma comunidade intelectual específica considera como canal principal de comunicação de conhecimento na sua área e como um dos árbitros da autenticidade ou legitimidade desse conhecimento. As revistas também delimitam padrões intelectuais, providenciam um espaço de comunicação entre pesquisadores, tornam públicas informações valiosas, contribuem no estabelecimento de diretrizes para a pesquisa e providenciam o registro histórico de uma área específica do conhecimento e, finalmente, conferem certificação implícita aos autores da autenticidade e originalidade do seu trabalho ${ }^{1}$. Além do que foi apontado, como já é sabido por todos os pesquisadores, as revistas científicas tem o potencial para servir aos seus interesses com vistas ao avanço e consolidação na carreira profissional científica e a recompensa pessoal do alcance de nível mais elevado de reconhecimento em termos de saber.

Sem as revistas científicas, o conhecimento estaria limitado a uma pequena audiência e teria uma vida curta, pois não haveria a sua disseminação, portanto se o objetivo do pesquisador é a descoberta, a busca de soluções e benefícios para o bem estar da humanidade, precisa adquirir a dimensão do que representam os trabalhos internos e a complexidade do fluxo no processo de publicação de uma revista ${ }^{2}$

Estas colocações foram registradas na intenção de destacar a importância do periódico científico como veículo que possibilita um espaço de comunicação de experiências construídas com bases científicas, com rigor metodológico e redigidas com cuidado, numa linguagem objetiva e acessível considerando que muitos serão os leitores. Também é importante destacar que o conhecimento gerado pelos autores dos trabalhos será referência para outros e exemplo para estudantes, assim a responsabilidade dos pesquisadores que enviam o trabalho para publicação não finaliza com o término da sua pesquisa, ela está apenas começando.

Com esta breve exposição espera-se que pesquisadores, no papel de autores, procurem entender as razões que levam os editores de revistas científicas a devolver artigos que foram encaminhados, na maioria das vezes, com a expectativa de serem publicados sem nenhuma restrição. A prática de aceite com mudanças ou mesmo a recusa do artigo não deve ser entendida como um fracasso, mas como uma oportunidade de aprimoramento científico e deve servir como um estímulo a continuar com a atividade de pesquisa.

Nos próximos editoriais serão discutidos outros tópicos a respeito de publicação científica, esta breve introdução por agora é suficiente.

\title{
Referências
}

1. Lafollete MC. Stealing into Print.Fraud, Plagiarism, and Misconduc in Scientific Publishing. Berkeley (CA): University of California Press; 1992.

2. Babor TF, Stenius K, Savva S, O'Relly J. Publishing Addiction Science: a guide for the perplexed. 2nd ed. Essex: World Health Organization and International Society of Addiction Journal Edictors; Multi-Science Publishing Company Ltd; 2008.

\author{
Margarita Antonia Villar Luis \\ Chief Editor of the SMAD, Revista Eletrônica Saúde Mental Álcool e Drogas, Full Professor of the University of São Paulo at Ribeirão \\ Preto College of Nursing, WHO Collaborating Centre for Nursing Research Development, Brazil, e-mail: margarit@eerp.usp.br.
}

